\title{
O alistamento eleitoral juvenil: reflexões sobre comportamento político e comportamento eleitoral da juventude no Rio Grande do Sul/Brasil
}

\author{
The youth electoral enrollment: considerations about political \\ behavior and electoral behavior of the youth in Rio Grande do \\ Sul/Brazil
}

\section{Patrícia R. C. da Cunha Camila Rodrigues Della Rocha}

\section{Resumo}

Este artigo tem por objetivo analisar o alistamento eleitoral da juventude gaúcha nos anos 2000-2012. Através da abordagem teórica de cultura política, utilizamos os achados sobre comportamento, comparecimento e participação política da juventude no Brasil e na América Latina para discutir a realidade local. O método utilizado é o quantitativo; analisando dados obtidos junto ao Tribunal Regional Eleitoral do Rio Grande do Sul, do Tribunal Superior Eleitoral-TSE, da Fundação de Economia e Estatística do Rio Grande do Sul; além de fontes secundárias de surveys como do IBOPE/2013 e do IBASE/2008.

\section{Palavras-chave}

Juventude; Alistamento Eleitoral; Comportamento Político; Comparecimento Eleitoral; Cultura Política.

\begin{abstract}
This article analyzes the electoral enrollment of the youth from Rio Grande do Sul between the years 2000 and 2012. Employing the theoretical approach of political culture, we utilize the findings about behavior, attendance and political participation of youth in Brazil and in South America to discuss local reality. We use a quantitative approach. The data analyzed were obtained by the Regional Electoral Court of Rio Grande do Sul, or by the Superior Electoral Court, and, by the Economics and Statistics Foundation. We also utilize secondary sources from surveys as the one from IBOPE/2013 and from IBASE/2008.
\end{abstract}

\section{Keywords}

Youth; Electoral Enrollment; Political Behavior; Electoral Attendance; Political Culture. 


\section{Introdução}

O tema da incorporação das massas populares à vida política de uma sociedade não é novo. É possível encontrar registros e densas reflexões nos tratados clássicos de filosofia política, principalmente, no século XIX, que reportam ao lento processo histórico vivido pelas sociedades ocidentais para garantir o direito ao voto universal. Para pensar os dias atuais, destaca-se a constatação de John Stuart Mill (MILL, 2001) sobre a inevitável ampliação do direito ao voto e sua preocupação com algo intrínseco ao processo político que é a existência de oposiçóes. A reflexão leva o autor a concluir que a participação política não é um privilégio de poucos e, portanto, é necessário que haja mecanismos para institucionalizar a participação ampliada.

Os mecanismos por excelência para institucionalizar a participação política nas sociedades contemporâneas são os partidos políticos, e a forma de participação ampliada encontrada é o voto universal. Entretanto, no século XX, observa-se a contestação dos partidos políticos enquanto mecanismo suficiente para garantir uma representação democrática caracterizando, o que ficou conhecido na literatura de Ciência Política como, a "crise da representação política" (POWER e JAMISON, 2005; LESSA, 2009; BAQUERO e VASCONCELOS, 2013). Por isso, entende-se o evento eleitoral como um fenômeno social que se materializa na "decisão de milhóes de indivíduos de participar do evento 'votar' e da direção do voto" (FIGUEIREDO, 2008, p. 15).

O crescimento das taxas de absenteísmo ou de votos brancos e nulos no Brasil (NICOLAU, 2002) contribui para aumentar a preocupação com o sistema político, mesmo que, a abstenção eleitoral seja um fenômeno comum nas sociedades desenvolvidas. Em países democraticamente estáveis como os Estados Unidos, a França, a Alemanha, a Grã-Bretanha, e tantos outros, a falta de participação dos eleitores é grande, mas isso não significa obrigatoriamente um questionamento da representatividade dos eleitos. A baixa participação eleitoral onde o voto é facultativo não compromete o exercício da política em sua essência, mas em sociedades como a brasileira, em que a herança autoritária ainda está presente nas relaçóes sociais e o voto é obrigatório, pode indicar um fator de instabilidade governamental.

Esse cenário se agrava quando considerado os resultados de pesquisas realizadas nas últimas décadas, que apontam para a desconfiança política dos cidadãos latino-americanos frente aos partidos e aos políticos (CEPAL, 2007; VALDIVIESO e LÓPEZ, 2007; RANINCHESKI, 2007). Se somada à insatisfação política expressas nas manifestaçôes ocorridas na América Latina no ano de 2013, em junho no Brasil e no Chile e em agosto na Argentina, protagonizadas em grande medida por jovens, a 
conclusão de que o sistema político apresenta problemas na região latino-americana torna-se evidente.

Segundo o Censo de 2010, havia no Brasil 51,3 milhóes de jovens de 15 a 29 anos de idade, o que equivale a cerca de $1 / 4$ da população do país. Particularmente, de acordo com o Tribunal Superior Eleitoral cerca de 23 milhóes e 500 mil jovens entre 16 e 24 anos de idade estão habilitados para as eleições gerais de 2014. Eles correspondem a quase $17 \%$ do total de 140 milhões de eleitores do Brasil, representando, portanto, um contingente significativo e capaz de decidir ou influenciar o destino político do país. Entre os jovens de 16 e 17 anos de idade, que tem direito ao voto facultativo, são 12 milhões de pessoas, e somente $2 \%$ requisitaram o título de eleitor para participar das eleiçôes de 2014. Mesmo não sendo possível aferir, neste momento, o impacto das manifestações ocorridas no país sobre as eleições majoritárias de 2014, destaca-se o comportamento político dessa população jovem como um fator determinante para os rumos eleitorais necessitando de uma reflexão mais cautelosa e longitudinal desse fenômeno.

$\mathrm{O}$ interesse em investigar o alistamento eleitoral que a população jovem apresenta no Rio Grande do Sul nos últimos anos se justifica dadas as transformaçóes na participação política dessa população, que incorpora novos repertórios às práticas políticas em conseqüência da utilização da internet e sai de uma aparente apatia para ação, que o comparecimento eleitoral tem para a legitimidade do regime democrático. Um novo posicionamento da juventude; compreendida como uma categoria social, "interclassista e comum a ambos os sexos, definida por uma condição específica que demarca interesses e necessidades próprias, desvinculadas da ideia de transição e suas instituições responsáveis" (ABAD, 2003, p. 23); chama atenção. Pesquisas nesse sentido colaboram com o valor da reflexão, uma vez que, existem poucas pesquisas que se voltam para investigar o alistamento e o comparecimento eleitoral dos cidadãos, e é mais raro as que investigam especificamente a juventude. Procurando contribuir para diminuição desta lacuna, este artigo investiga o alistamento eleitoral da juventude no Rio Grande do Sul (RS)-Brasil.

\section{Cultura Politica - uma abordagem para participação politica juvenil}

No campo da Ciência Política, os estudos de cultura política se diferenciam ao se voltarem para dois aspectos em particular: o objeto de estudo e os métodos e técnicas de pesquisa (PASQUINO, 2000). Em relação ao objeto de estudo, voltamse, sobretudo, para o homem como ator político, e examinam não só as suas ações, como também as suas motivações, atitudes, expectativas, tendências e interrogações, 
tendo como foco a personalidade e a atividade política dos sujeitos. Em relação ao método e às técnicas a serem usados no estudo da política, priorizam os métodos científicos inspirados no modelo das ciências naturais e em novas técnicas de pesquisa, como entrevistas, sondagens de opinião, painéis, análise de conteúdo, simulação e técnicas quantitativas.

A obra The Civic Culture, de Gabriel Almond e Sidney Verba (1963), pode ser vista como um marco na investigação científica de Ciência Política. Eles definiram o arranjo mais adequado ao surgimento e à manutenção de um regime democrático como sendo uma Cultura Cívica. Esta agrega vários dos valores e comportamentos apregoados como essenciais pelas teorias alternativas de democracia como a participativa e a deliberativa, devendo, portanto, promover maior capacidade comunicativa e persuasiva dos cidadáos, busca de consensos, e maior profundidade no debate político. Enfim, uma cultura política que promove valores de tolerância e princípios inclusivos e participativos condizentes com a democracia.

Para Almond e Verba (1963), os casos empíricos mais próximos de um regime democrático ideal seriam os Estados Unidos e o Reino Unido. Esses estudos teriam inspirado os autores na definição do conceito de cultura política entendido como "as disposiçóes psicológicas dos indivíduos sobre o sistema político e sobre o papel do cidadão nesse sistema” (ALMOND E VERBA, 1963, p. 97) A defesa propagada pelos autores de que os países que se distanciam de uma cultura política como a dos britânicos e a dos norte-americanos comprometem o desenvolvimento da democracia recebeu diversas críticas voltadas ao determinismo e ao caráter etnocêntrico das conclusões apontadas (ALMOND e VERBA, 1963).

Apesar das fortes críticas enfrentadas pelo conceito de cultura cívica, a compreensão de que é necessária a existência de uma cultura política composta por valores democráticos para que o sistema tenha sustentabilidade resistiu e foi retomada nos anos posteriores. Segundo Rennó Jr. (1997), os estudos de cultura política têm sido alvo de diversas críticas e renovados interesses desde a pesquisa de Almond e Verba. Porém, é inquestionável a contribuição destes para o debate acerca da construção democrática, e a participação cidadã. Constituem-se, assim, em instrumental teórico particularmente relevante para a análise do comportamento político dos cidadãos.

É através da formação e expansão da sociedade civil que a participação política tem sido valorizada e compreendida como ingrediente necessário para construçáo e estabilidade do regime político em países de democracia recente como o Brasil. E é em decorrência do debate democrático brasileiro que a criança e a juventude sofrem alterações no seu status de cidadania. Vistos até entáo como extensão de seus pais e 
cidadãos em potencial, ou cidadãos do futuro, essa camada da população tinha seus direitos e deveres vinculados e decorrentes da família. Sua responsabilidade era de âmbito exclusivo da esfera privada. As mudanças sociais ocorridas, sobretudo, nas décadas de 1980 e 1990 no país, e a própria participação política ativa da juventude no processo de democratização e no debate sobre os novos papéis sociais dessa categoria, seus direitos e deveres, culminaram com o reconhecimento oficial da condição de cidadãos das crianças e adolescentes, através do Estatuto da Criança e Adolescente - ECA. A responsabilidade pelo reconhecimento de direitos e deveres de crianças e adolescentes não é mais exclusivamente de âmbito privado, mas passa a ser uma responsabilidade social, e o espaço para esta cidadania ativa está reconhecido, mesmo que pouco ocupado.

A concepção do/a jovem enquanto cidadão/ã, alguém que escapa do âmbito e responsabilidade exclusiva da esfera privada, náo é um processo isolado, mas alia-se aos processos de redemocratização no Brasil e na América Latina. A juventude passa a ser representada como uma etapa específica do ciclo vital, no qual o trânsito da infância para a maturidade implica um período "em que se desassocia a maturidade biológica da moral e da social” (HOPENHAYN, 2005, p.136). A mudança no papel social desempenhado pela juventude brasileira faz com que a partir da Constituição de 1988 os jovens de 16 e 17 anos conquistem o direito ao voto facultativo, sendo a juventude delimitada por cidadáos de 15 a 18 anos. Contudo, o processo de construção da identidade juvenil enquanto categoria social específica portadora de direitos e deveres, demandante e interlocutora legitima do Estado é lento. Dessa forma, só em 30 de junho de 2005 a Política Nacional de Juventude (BRASIL, 2005) foi criada no Brasil; ampliando a faixa etária de determinação da juventude de 24 para 29 anos. Enquanto, o reconhecimento legal da categoria juventude, para além da adolescência que se encerra aos 18 anos, só se efetiva em julho de 2010 com a aprovação pelo Congresso e pela Presidência da República da Emenda Constitucional No 65; sendo a regulamentação dos direitos, políticas públicas e diretrizes da Política Nacional de Juventude sancionado pela presidência em agosto de 2013 através do Estatuto da Juventude (BRASIL, 2013).

O processo de reconhecimento da juventude no Brasil, como agentes sociais capazes de influir na agenda pública, ou seja, no sentido em que a utiliza Groppo (2000), inspirado no conceito de grupo social concreto de Mannheim (1982), como uma categoria social que se torna ao mesmo tempo "uma representação sociocultural e uma situação social” (GROPPO, 2000, p. 7) teve e tem de combater a herança de concepçóes diversas sobre a juventude muitas vezes desfavorável à categoria. No Brasil, principalmente até a década de 1980, como aponta Ângela Pinheiro: 
44 | Patrícia R. C. da Cunha e Camila Rodrigues Della Rocha

A criança e o adolescente concebidos como objetos de controle e disciplina, têm sido alvo de práticas que se voltam para a prevenção da delinquência e para a integração social, de forma que contribuam, de maneira produtiva, para o desenvolvimento do País (2001, p. 51).

Para Pinheiro, é no início dos anos de 1980 que se localizam as ações de articulação entre Estado e sociedade que promovem uma "luta simbólica entre princípios fundantes de experiências" (PINHEIRO, 2001, p. 58), no trato público da criança e do adolescente, que por sua vez principiam a promoção de uma nova forma de representação social destes como sujeitos de direitos. Já Sposito (2003) considera que o marco das açôes para juventude no Brasil pode ser identificado em 1997, quando ações públicas do Governo Federal são endereçadas ao segmento específico da juventude. Contudo, destaca-se nessas ações a condição de "risco social" que era atribuída à juventude brasileira, relacionando essa população à imagem de violência e delinquência.

Ao mesmo tempo em que é questionada a imagem da juventude como vítima ou "risco social" é possível observar uma série de eventos internacionais que vão influir positivamente para que o tema da juventude adentre a agenda pública brasileira e passe a ser alvo de políticas públicas, não apenas no país, mas em toda a América Latina. Isso começa pelo Ano Internacional da Juventude: participação, desenvolvimento e paz (em 1985), seguidos por diversos outros eventos, que se somam aos Fóruns Mundiais de Juventude, que funcionam como canal de comunicação entre as organizações da juventude e os órgãos e organismos especializados das Naçóes Unidas, que ocorrem em 1991 e 1996 na Áustria, em 1998 em Portugal, e em 2001 no Senegal. Os eventos contribuem para destacar o papel de Organismos Internacionais como a UNESCO no incentivo e detecção de um novo comportamento para juventude, o de protagonista e agente do desenvolvimento. Um exemplo disso é o relatório da UNESCO produzido por Castro e Abramovay (2002), que constata que a juventude náo aceita mais o papel de passividade.

Nesse cenário, o papel da participaçáo juvenil tem figurado como conceito chave para inspirar instituições que se organizam na forma de Secretarias da Juventude ou Conselhos na região latino-americana. São novas instituições, que ganham relevância ao procurar conectar instâncias de governos e políticas implementadas em níveis locais ou regionais, que têm apresentado soluçôes criativas às políticas públicas. No Brasil, mobilizaçôes sociais vinculadas à defesa dos direitos da juventude procuram promover o diálogo junto ao governo para propiciar a integração social desta modificando a relação da juventude com a política no país. 
Entretanto, apesar das conquistas realizadas pela organização da juventude enquanto categoria social, o desenvolvimento desse processo nas duas últimas décadas não livrou a juventude da atribuiçáo de apatia e comodismo. Essa imagem da juventude causou surpresa quando o Ibope $(\mathrm{G} 1,2013)$ mostrou que $43 \%$ dos manifestantes que inundaram as ruas do Brasil nos protestos de junho e julho de 2013 tinham entre 14 e 24 anos.

A pesquisa do Ibope (2013) demonstrou que os principais problemas brasileiros para essa população são a corrupção, citada por $63 \%$ dos entrevistados (sendo citada em primeiro lugar por $49 \%$ deles). Já na pesquisa Agenda Juventude Brasil (2013), a corrupção é citada por 67\% (sendo 36\% de forma direta) e o poder dos traficantes foi mencionado por $46 \%$ (sendo $13 \%$ como primeira opção); a grande desigualdade entre ricos e pobres, escolhido por $42 \%$ (sendo $20 \%$ na primeira posiçáo); e o racismo e outras formas de discriminação (34\%). No que diz respeito, por fim, aos assuntos a serem discutidos com a sociedade em geral, foram citados principalmente: desigualdade social e pobreza (40\%), drogas (38\%), violência (38\%), política $(33 \%)$, cidadania e direitos humanos $(32 \%)$, educação e futuro profissional (25\%), racismo (25\%) e meio ambiente e desenvolvimento sustentável (24\%).

A respeito da cultura política no Rio Grande do Sul, Baquero e Prá (1995), ao analisarem os padróes de participação política constataram uma pequena tradição de participação entre os gaúchos e um processo de afastamento da política por parte dos cidadãos, em virtude da desilusão com as políticas públicas e com a situação de crise vivenciada pelo país. Nessa perspectiva, a ausência de participação política associa-se a quatro fatores: a) apatia ou falta de interesse pela política; b) cinismo ou suspeita em relação à política; c) alienação ou indiferença em relação à política; 4) anomia ou perda de valores e de vontade de participar (BAQUERO e AMORIM, 2004).

Destaca-se que a juventude tem se distanciado das formas de participação política classificadas como convencionais, que envolvem votar e se filiar a partidos políticos, e se identificado com formas de participaçóes não convencionais, como abaixo-assinados, manifestações de rua e etc. (CUNHA, 2005; NICOLETTI, 2013). As novas tecnologias de comunicação, que minimizam os custos da organização das açóes coletivas, têm contribuído para promover novas formas de participação. Essa realidade está constituindo um novo comportamento político da juventude que se reflete no comparecimento eleitoral?

\section{Comportamento politico e Alistamento Eleitoral Juvenil}

O alistamento eleitoral é um tema relevante para pensar a qualidade e estabilidade do regime democrático, isso porque, envolve dois aspectos fundamentais 
para saúde desse regime político, que é a questão da legitimidade e da estabilidade política. Desde, a proposta exposta em "O Federalista", nos jornais dos EUA, que a democracia representativa tornou o processo eleitoral fundamental para garantir a legitimidade do regime político democrático. Mesmo para aqueles que compreendem o regime democrático como algo mais que uma forma de escolha de representante (SCHUMPETER, 1961), as eleiçóes significam uma etapa importante para legitimação dos governantes, e sua condução e a participação dos cidadãos no processo um indício da estabilidade vigente, ou não, em uma sociedade.

A compreensão da importância do comportamento do cidadão frente ao processo eleitoral de um sistema democrático, e em particular, de sistemas democráticos recentes como acontece com o Brasil, chama atençáo para o alistamento eleitoral das novas gerações, uma vez que, a faixa etária da juventude de 16 a 18 anos, para quem o voto é facultativo, representa hoje cerca de 12 milhóes de pessoas, com peso suficiente para decidir eleiçóes e ajudar a mudar a cara da política brasileira. Segundo números do Tribunal Superior Eleitoral (TSE, 2014), a média de novos votantes entre 16 e 18 anos no país tem sido de 2 milhóes a cada pleito e neste ano de 2014 já está garantido quase 1 milhão.

Considerando a obrigatoriedade do voto no Brasil e constatado essa renovação, o debate sobre o comparecimento eleitoral parece ser relativamente simples, pois envolve a ação de comparecer ou não as urnas. Contudo, ele pode assumir abordagens distintas e esconder aspectos relevantes quanto ao comportamento político da população. $\mathrm{O}$ não comparecimento às urnas pode se dar por motivos diversos, que vão desde a impossibilidade de ir ao local de votação até o ato proposital de não se habilitar para eleições através da obtenção do título de eleitor, ou seja, o não alistamento. Pode refletir, também, comportamentos variados que vão da apatia ao protesto, e motivaçóes subjetivas do eleitor que refletem da alienação a satisfação ou a insatisfação política.

A discussão sobre o alistamento e comparecimento eleitoral, na maioria das vezes, adota três grandes perspectivas, as de orientação sociológica, a de cultura política e a institucionalista. Na primeira, os fatores estruturais de uma sociedade, como os socioeconômicos e globais influenciariam o comportamento do eleitor a cada pleito; a segunda considera o comportamento político e a participação dos eleitores como o resultado combinado dos valores, crenças e percepçóes dos indivíduos interagindo com as instituiçóes para explicar o comparecimento eleitoral; e na última, o peso das instituições, como regras eleitorais, formato do Estado, atuação das instituições políticas, como os partidos, é considerado o principal fator de determinação da participação do eleitor. Filiando-se a perspectiva da cultura política 
cabe, então, verificar as pesquisas feitas sobre as condições que influenciam no comportamento do eleitor em geral para, então, partir em direção de um detalhamento dessas influências no comportamento juvenil.

A autora Denise Salles (2010), ao tentar explicar quais os motivos que levaram às mudanças eleitorais ocorridas na América Latina nos últimos anos, desenvolveu uma pesquisa que relaciona a cultura política com o comparecimento eleitoral no Brasil. Nessa pesquisa se busca determinar quais as variáveis já analisadas pela literatura, além da obrigatoriedade do voto que levam os brasileiros ao comparecimento às urnas. A autora concluiu que a participação em associaçóes em geral aumenta consideravelmente as chances de participação eleitoral. A participação em associaçóes de caráter político demonstra um aumento de $116 \%$ nas chances de comparecimento. Já nas associações não governamentais, embora haja um aumento nas chances de votar, esse aumento não parece tão significativo, e se consideradas as ONG's ou grupos ambientalistas, as chances de participação tendem a diminuir (SALLES, 2010, p. 18-19).

Salles (2010, p. 19) ainda concluiu que a educação exerce um importante papel no desenvolvimento da cultura política. A cada ano de educação do indivíduo, as chances de ele votar crescem $8 \%$. Além da educação, também tem importância a confiança. Quando considerada em relação aos partidos políticos, essa determina um aumento de $15 \%$ na possibilidade de voto. Já a confiança interpessoal e a satisfação com a democracia não apresentam variação no comparecimento eleitoral.

Miguel Carreras e Néstor Castaneda-Angarita (2012), da Universidade de Pittsburgh, também desenvolveram um estudo no qual analisaram os determinantes da participação eleitoral na América Latina. Através de pesquisas teóricas e empíricas os autores exploraram fatores individuais e socioeconômicos para chegarem aos seus resultados. Concluíram que os fatores idade e educação são os que mais influenciam na participação eleitoral na América Latina. Assim como Salles (2010), apontam que quanto maior for a escolaridade, maiores sáo as chances de participação no processo eleitoral, e essa probabilidade aumenta consideravelmente nas eleiçôes presidenciais. Quanto ao fator idade, sustentam que quanto mais velho for o indivíduo, mais propenso ele será à participação.

Ribeiro, Borba e Silva (2012) buscam realizar um estudo comparado dos determinantes do comparecimento eleitoral na América Latina. Através de uma análise multinível, os autores procuram combinar em um único modelo variáveis cujos níveis analíticos são distintos, para considerar variáveis individuais como: educação, renda, estado civil, crenças e valores; e as macroestruturais, como: Produto Interno Bruto (PIB) e variáveis que traduzem a situação da economia dos países, 
características do sistema eleitoral e situação das liberdades políticas e individuais dentre outras.

Os resultados encontrados pelos autores ressaltam descobertas importantes. Dentre elas destaca-se que a urbanização é um fator que eleva em mais de $10 \%$ a chance de comparecimento eleitoral, e que o voto obrigatório é uma das variáveis de maior significância testada. Os fatores escolaridade e idade se confirmaram como preditores importantes para o comparecimento eleitoral, aumentando em $4 \%$ a cada ano a mais de escolaridade, e em mais de $4 \%$ cada ano a mais de vida as chances de comparecimento eleitoral. Dentre as variáveis que não se mostraram significativas para explicar um maior comparecimento eleitoral destaca-se o PIB per capita e a efetividade dos governos. Os autores chamam atenção para o fato de a baixa efetividade do governo aumentar as chances do eleitor latino americano comparecer às urnas. Já variáveis relacionadas ao posicionamento político como a escolha da democracia enquanto melhor forma de governo aumenta em $40 \%$ as chances de comparecimento eleitoral, e variáveis atitudinais como a percepção de que as eleições são limpas eleva em $50 \%$ as chances de comparecimento às urnas.

As descobertas de Ribeiro, Borba e Silva (2012) contribuem com este trabalho em dois aspectos específicos: a) ao reforçarem os diagnósticos de que a idade é um preditor importante para o comparecimento eleitoral, aumentando a relevância de compreender o comportamento da juventude frente ao processo eleitoral; b) e a comprovação de que variáveis atitudinais, crenças e percepções são altamente significativas para explicação do comportamento eleitoral dos cidadãos.

Tais descobertas são enriquecidas pela pesquisa de Keil (2004) realizadas com jovens do Rio Grande do Sul, onde a autora busca comparar o comportamento político da juventude universitária que nasceu em 1968 e viveu o período de ditatura militar no Brasil com o comportamento político de jovens universitários, de 16 a 21 anos, do inicio dos anos 2000, com o país já democrático a mais de dez anos. O intuito da autora era responder a questáo:

Tendo em vista que os jovens estão fortemente relacionados com o movimento de seu tempo, hoje um tempo de inquietude e de grandes transformações, quais desejos e participaçóes os jovens contemporâneos expressam na arena política? Existe, nesse sentido, alguma relação com seus antecessores? (KEIL, 2004, p. 20).

As respostas encontradas, por Keil (2004), apontam para diferenças resultantes dos contextos-meios em que viveram esses jovens. A geração que viveu sobre a ditadura apresentava um engajamento político fruto não apenas da busca por 
um novo regime político, mas também pela conquista de direitos civis e políticos; pelo desejo de modificar estruturas de classes enquanto expressões das relaçóes de poder decorrentes das estruturas da produção capitalista, e/ou quebrar hierarquias sociais estabelecidas. Ainda segundo a autora, esta geração de jovens era muito mais engajada do que a geração de jovens contemporâneos, que "parecem não possuir uma convicção arraigada dos valores da democracia” (KEIL, 2004, p. 28); faltando-lhes afeto pela política.

Em relação aos jovens contemporâneos da pesquisa, Ivete Keil (2004) observou que eles/as se sentiam excluídos da realidade política e das decisóes dos governantes se desinteressando pela política. Na perspectiva da autora, isso acontecia porque as atitudes e comportamentos políticos são apreendidos, e a expectativa de uma sociedade sobre seus jovens é essencial para o desempenho dessa juventude. $\mathrm{O}$ problema posto no texto é que o Brasil não apresenta um projeto próprio que possibilite aos jovens uma compreensão da realidade social, econômica e política contemporânea. Não permitindo essa juventude tecer uma ligação entre a esfera política e a econômica, raramente saindo da esfera individual das preocupaçóes econômicas. Tal situação gera desconfiança em relação aos políticos e a política, um desencantamento e um pessimismo que perpassa algumas expressóes de protesto e a vontade de engajamento individual. Contudo, o engajamento encontrado aponta para uma transformação na forma da juventude atuar em sociedade se voltando para pequenas ações, resoluçóes de problemas cotidianos, com o intuito de simplesmente melhorar as coisas. Nesse contexto, uma vez que se sentem frustrados com a política e impotentes para influenciar em mudanças sociais maiores, ações como o voluntariado aparecem como possibilidade de engajamento para esses jovens. Essas ações, apesar de associativas, desmobilizam o pertencimento a uma rede ideológica, promovendo um engajamento "despolitizado" e por isso mesmo valorizado pela juventude.

No que tange particularmente ao voto, Keil (2004) destaca a influencia dos meios de comunicação e do meio familiar para o posicionamento político da juventude contemporânea gaúcha pesquisada. Em sua maioria eles/as tendiam à esquerda e a família era a principal referência para aproximação ou distanciamento desse posicionamento político. A maioria defendia o voto como direito, mas mesmo entre esses havia os que não votaram aos 16 anos. Para a autora a compreensão do voto para os/as jovens pareceu frágil e sua memória eleitoral também.

Sobre o comportamento eleitoral no Rio Grande do Sul a pesquisa de Elis Hardman (2001), que pesquisou cidades do interior do estado, conclui que o comportamento cético e personalista da maior parte dos eleitores pesquisados caracteriza-se como emotivo, pois é suscetível a uma adesão intuitiva em relação a 
determinadas candidaturas, sendo, portanto, a decisão do voto uma ação sensível e emocional. Este eleitor apresenta baixa sofisticação política, com baixo nível de participaçáo política e um distanciamento em relação às instituiçóes política como os partidos políticos.

Tal cenário enfatiza as dificuldades para socialização de valores democráticos pela juventude brasileira. Lucas (2004a) postula que há uma ideologia da antipolítica na cultura política juvenil no país. Indo na mesma direção de estudos de capital social (BAQUERO e BAQUERO, 2007; BAQUERO, 2004; SCHMIDT, 2004; LUCAS, 2004b; NAZZARI, 2006), o autor ressalta a desconfiança e o baixo engajamento político da juventude, porém destaca a capacidade da abordagem de antipolítica para captar se a intolerância, descrédito e apatia dos/as jovens se transformaram em aversão à política (LUCAS, 2004a). Ele pesquisa a família, a escola e os meios de comunicaçáo enquanto agências de socializaçáo, para verificar sua influência na produção de um efeito político sobre os/as jovens. Demonstra, ainda, que essas agências favorecem as atitudes pró-políticas quanto maior a frequência de seu contato com os jovens, mesmo que isso não signifique maior participação política da juventude. Observa, também, uma diferença na socialização de jovens de escola pública e privada, sendo os últimos mais propícios a uma postura antipolítica relacionada à tecnocracia, enquanto os primeiros a uma postura antipolítica governamental, com maior rejeição aos partidos políticos. Entretanto, o pesquisador chama atenção para o fato de a socialização ser cada vez menos política na relação entre as geraçóes (LUCAS, 2004a).

O processo de formulação e orientação de valores, que se volta para a formação de atitudes políticas, por sua vez, chama atenção para as práticas políticas na sociedade brasileira. Elas têm gerado nos/as jovens cidadãos/ãs uma cultura política que João Pedro Schmidt (2001) vai chamar de "cultura política híbrida",

[...] que demonstra preferência pela democracia num sentido abstrato, baixa eficácia política, descrença nos políticos e nas instituiçóes, sensibilidade para ideais de mudança, mas sem orientaçóes ideológicas definidas, pequena participação política efetiva. [...] uma cultura marcada pela presença tanto de elementos democráticos como autoritários, de descrença e de apatia (SCHMIDT, 2001, p. 142).

Essa cultura política híbrida pode ser percebida nos dados da pesquisa do IBASE (2008), quando os entrevistados são questionados sobre quais as ações que consideram mais importantes para melhorar as suas vidas. A maior parte dos brasileiros pesquisados demonstra uma postura individualista, ao optar pelo esforço 
próprio como resposta $(44,3 \%)$, estando os jovens $(48,7 \%)$ um pouco mais identificados com essa posição (adultos, 42,2\%). A reafirmação individual de capacidade contrasta com a desvalorização e descrença na açáo social como resposta para essa questão, pois apenas $4 \%$ dos respondentes optaram por sua participação em organizações sociais como resposta. Nesse caso, os jovens mostram uma ligeira superioridade $(4,4 \%)$ frente aos adultos $(3,8 \%)$.

Tal cenário sugere que o Brasil vive uma crise de legitimidade e credibilidade perante a população jovem do país, nos termos que diagnóstica Baquero (2007). Definindo crise como "o momento histórico em que as contradições de um sistema político não conseguem ser superadas pelas instituiçóes vigentes de regulação de conflito", o autor aponta para uma situação onde falta as "bases de uma estabilidade política que permita a adoção de políticas de longo prazo” (p. 57).

\section{Análise dos Dados}

A juventude brasileira constitui um dos maiores segmentos da população. Há em torno de 51 milhóes de jovens entre 15 e 29 anos no Brasil segundo o censo do IBGE (2010). Essa população, dado sua heterogeneidade tem sido subdividida, até para efeitos de políticas públicas como faz a Secretária Nacional de Juventude, como jovens adolescentes (15-17 anos) e jovens adultos (18-29 anos). Consideram-se nesse caso as diferenças de fase da vida, interesses, responsabilidades, necessidades e comportamentos para operar essa divisão. Tal concepção será considerada neste trabalho, pois se reflete nas próprias regras de alistamento eleitoral, onde os jovens adolescentes têm a opçáo de participar das eleiçóes como votante, enquanto os jovens adultos têm a obrigação ou dever de participar das eleiçóes no país.

O direito dos jovens ao voto foi adquirido através de um processo histórico longo, que foi gradativamente abrangendo maiores grupos etário. Com a Constituição de 1988, jovens entre 16 e 17 passaram a ter o direito ao exercício do voto, sem, no entanto, ter a obrigaçáo de exercê-lo. Mesmo sendo o voto uma faculdade, em 1992 chegava a 3.221.480 o número de jovens alistados como eleitores no Brasil. Esse número veio diminuindo gradativamente ao longo dos anos chegando a 1.638.469 em 2014. No Estado do Rio Grande do Sul, em 1992 o número de jovens aptos a votar era de 161.902, e em 2014 esse número caiu para 67.130.

É importante lembrar que o alistamento eleitoral se relaciona de forma direta e inequívoca com o comparecimento eleitoral, pois sem título de eleitor o cidadão náo pode exercer seu direito de voto no Brasil. Deve ser considerado, também, que a faixa etária de juventude foi alterada em 2005 para 29 anos e que os existentes sobre 
juventude trabalhavam com o limite anterior 24 anos. Em conseqüência adota-se, neste trabalho o recorte etário de 16 a 24 anos para análise dos dados.

Se considerado o cenário atual, verifica-se uma diminuição no eleitorado jovem para o grupo etário com idades entre 16 e 24 anos. Esses eleitores/as representavam em 2010, 22,8\% do eleitorado brasileiro, e 19\% do eleitorado gaúcho. Eles/as representam hoje, $16,15 \%$ do eleitorado no Brasil e $14,06 \%$ no RS. Isso significa que, apesar da diminuição, a juventude tem um peso eleitoral considerável nas principais eleições majoritárias, que ocorrem simultaneamente no Brasil; por exemplo, em 2014 teremos eleições para presidente e para governador do estado.

Entretanto, apesar do potencial eleitoral dessa categoria social, o fenômeno que se observa é a diminuição do alistamento da população juvenil e consequente comparecimento eleitoral. Tal fato não pode ser atribuído ao envelhecimento da populaçáo brasileira, conforme quadro abaixo. O que reforça as interpretaçóes da literatura sobre o distanciamento dos jovens da política (BAQUERO, 2004; SCHMIDT, 2004; LUCAS, 2004b; NAZZARI, 2006).

Quadro 1 - População juvenil de 15 a 24 anos e eleitorado juvenil de 16 a 24 anos do RS nos anos eleitorais de 2002 a 2010

\begin{tabular}{|c|c|c|}
\hline NAno & População do RS entre 15 e 24 anos & $\begin{array}{c}\text { Número de eleitores no RS de 16 e 24 } \\
\text { anos }\end{array}$ \\
\hline 2002 & 1.836 .552 & 1.380 .468 \\
\hline 2006 & 1.807 .467 & 1.346 .061 \\
\hline 2010 & 1.746 .643 & 1.274 .163 \\
\hline
\end{tabular}

Fonte: FEE (2013) e TSE (2014).

O Brasil possui um intenso calendário eleitoral, uma vez que ocorrem eleições de dois em dois anos para níveis de representação diferentes. O quadro acima contempla os anos em que ocorreram processos eleitorais mais amplos, envolvendo eleiçóes combinadas para cadeiras no Executivo, como presidente e governador, e no Legislativo, como deputado federal e deputado estadual. Chama atenção que, apesar da pequena diminuição da população de jovens, cerca de 100 mil, de 15 a 24 anos na unidade federativa do Rio Grande do Sul (RS), em quase uma década o número de eleitores de 16 a 24 anos diminuiu 2,22\%, que representa 106.305 jovens votantes a menos, para o mesmo período.

Se comparada a população de 16 a 24 anos que possui título de eleitor com a populaçáo de 15 a 24 anos existente no RS, é possível obter uma porcentagem aproximada do que esses eleitores representam em relação à população jovem. No ano de 2002 os/as jovens entre 16 e 24 anos que possuíam título de eleitor representavam 
cerca de $75,16 \%$ da população da juventude gaúcha; já nas eleições de 2006, essa porcentagem caiu para 74,47\%; enquanto no ano de 2010 os jovens aptos a votar perfaziam $72,94 \%$ da populaçáo juvenil. Embora a diminuição na porcentagem de eleitores possa parecer pequena, refere-se a 456.084 jovens que deixaram de votar no ano de 2002, enquanto 461.406 jovens deixaram de votar no ano de 2006, e 472.480 jovens se ausentaram do processo eleitoral de 2010 no RS.

É possível considerar que as eleições para presidente, governador e Assembléias Legislativas digam respeito a realidades mais distantes da juventude; que apesar de campanhas publicitárias específicas para incentivá-la a participar do processo eleitoral, essa juventude acredite ter pouca influência no processo, desconsiderando ou desconhecendo o peso eleitoral que representa. Dessa feita, o comportamento da população juvenil deveria apresentar modificações ao tratar de pleitos locais, mais próximos de sua realidade. Mas há de se considerar, também, as verificações de Keil (2004) sobre o engajamento de a juventude gaúcha se voltar para pequenas açóes e resoluçóes de problemas cotidianos por se sentir frustrada e descrente nas grandes transformaçóes sociais.

Quadro 2 - População juvenil de 15 a 24 anos e eleitorado juvenil de 16 a 24 anos do RS nos anos eleitorais de 2000 a 2012

\begin{tabular}{|c|c|c|}
\hline Ano & População do RS entre 15 e 24 anos & $\begin{array}{c}\text { Número de eleitores no RS de 16 e 24 } \\
\text { anos }\end{array}$ \\
\hline 2000 & 1.822 .708 & 1.355 .057 \\
\hline 2004 & 1.832 .135 & 1.444 .165 \\
\hline 2008 & 1.770 .079 & 1.314 .266 \\
\hline 2012 & 1.732 .649 & 1.254 .929 \\
\hline
\end{tabular}

Fonte: FEE (2013) e TSE (2014).

O quadro acima demonstra dados relativos às eleiçóes para prefeito e vereadores no RS. Como é possível observar, a população de jovens diminuiu ao longo de pouco mais de uma década, assim como o eleitorado na mesma faixa etária. Entretanto, ao serem comparados ambos os dados constata-se que a diminuição do eleitorado ocorreu em maior escala. A porcentagem da população que possuía título de eleitor no ano de 2000 e no de 2012 diminuiu 1,92\%. No ano de 2000, 74,34\% da população entre 16 e 24 anos estavam alistados. Em 2004 houve um aumento nesse grupo de eleitores na casa de 4,58\%, que passou a representar 78,82\% da população jovem. Já na eleição seguinte, há uma queda mais expressiva nesse número, e os eleitores jovens passam a representar $74,24 \%$ da população com idades entre 15 e 24 anos, retornado a patamares próximos aos encontrados no ano de 2004. No ano 
de 2012, porém, o número cai ainda mais e o eleitorado jovem passa a ser $72,42 \%$ daquela população. A variação do alistamento juvenil, independente do crescimento vegetativo dessa população, demonstra mudanças nos humores participativos em relação à política que vão além da simples obrigatoriedade do voto. Obviamente o contexto político torna-se um fator de peso para explicar a alta no alistamento de 2004 .

Observando e comparando os quadros 1 e 2 é possível verificar que independente do escopo da eleição os índices de alistamento eleitoral da juventude gaúcha se mantém acima de 70\%. Apesar de parecer um índice elevado deve-se considerar que a maior parte desta população está dentre aqueles que têm obrigação de votar. A diminuição no alistamento eleitoral aponta indício de redução dentre as camadas mais jovens da categoria juvenil, que tem direito ao voto facultativo, o que reforça a literatura discutida (SALLES, 2010; CARRERAS e CASTANEDAANGARITA, 2012; RIBEIRO, BORBA e SILVA, 2012), que chegou a conclusão de quanto menor a idade menor o comparecimento eleitoral. Entretanto, só pesquisas mais aprofundadas e dirigidas podem indicar se o distanciamento dessa população de 16 e 17 anos do processo eleitoral se dá por causa da falta de maturidade do seu período de vida ou de um descrédito e desconfiança em relação a política e aos representantes.

Os dados apresentados ressaltam uma discrepância no processo gradativo de diminuição do alistamento eleitoral da juventude gaúcha no ano de 2004 para os processos eleitorais locais (Quadro 2), que não se verificam quando observado a sucessão do alistamento para os pleitos de eleições mais gerais (Quadro 1). Uma possível explicação para esse acontecimento é o realinhamento partidário de candidatos a prefeitos em virtude da mudança do bloco de alianças que elegeram o presidente da República no ano de 2002, mas tal hipótese necessita de verificação.

\section{Conclusão}

A legitimidade e a estabilidade política de um regime democrático dependem diretamente do comportamento político apresentado pela população. A baixa participação eleitoral em uma sociedade que tem voto obrigatório pode representar a instabilidade da democracia. Tentando determinar as razoes que influenciam o comportamento político dos cidadãos, diversos autores apresentam valores e percepçóes que compóe a cultura política da sociedade, tentando justificar os baixos índices de participação. A desconfiança em relação às instituiçóes e aos partidos políticos são fatores que comprometem a busca da população por seus direitos de 
cidadão, o que se reflete em um afastamento que se caracteriza não só nas urnas, mas, antes disso, no alistamento eleitoral.

É possível concluir que há uma diminuição efetiva no eleitorado juvenil brasileiro que não está associada à diminuição da população jovem no Brasil. No estado do Rio Grande do Sul, através da análise dos dados apresentados nos quadros 1 e 2, é possível verificar um comportamento eleitoral que se caracteriza pela queda na busca pelos direitos eleitorais por parte da população mais jovem. Mesmo considerando a obrigatoriedade do voto a partir dos 18 anos e as punições vinculadas ao descumprimento da lei, pessoas com idades entre 16 e 24 anos tem demonstrado um afastamento da política que pode ser observado na queda da procura desses jovens pelo título eleitoral. Tal situação remete a uma crise de legitimidade e credibilidade perante a população jovem do país; nos termos que diagnóstica Baquero (2007).

Além disso, os dados apresentados demonstram diferenças comportamentais quanto aos distintos períodos analisados. Observa-se uma queda contínua no alistamento eleitoral referente ao período das eleiçôes gerais, enquanto há certa variação em relação ao alistamento no período das eleiçóes locais demonstrando que a maior proximidade ou distanciamento do âmbito eleitoral é uma variável importante para compreensão do comportamento eleitoral da população jovem. O número de jovens alistados ao logo do período de 12 anos se apresenta acima dos $70 \%$, o que ainda é uma porcentagem alta. Mas a queda continua no período apresenta uma modificação comportamental que merece ser destacada.

Patrícia R. C. da Cunha é Professora. do Programa de PósGraduação em Ciência Politica da Universidade Federal de Pelotas. E-mail: pattyycunha@yahoo.com.br.

Camila Rodrigues Della Rocha é Mestranda do Programa de Pós-graduação em Ciência Política da Universidade Federal do Rio Grande do Sul. E-mail: camiladelarocha@gmail.com.

\section{Referências}

ABAD, Miguel. Crítica política das políticas de juventude. In: FREITAS, Maria V. de; PAPA, Fernanda de C. (Orgs.). Políticas Públicas: juventude em pauta. São Paulo: Cortez/Ação Educativa Assessoria, Pesquisa e Informação/Fundação Friedrich Ebert, 2003. p. 13-22. 


\section{AGENDA JUVENTUDE BRASIL. Pesquisa Nacional Sobre o Perfil e Opiniáo dos Jovens Brasileiros} 2013. Ago. 2013. Disponível em: <http://bibspi.planejamento.gov.br/bitstream/handle/iditem/174/Pesquisa\%20Lan\%C3\%A7amen to_Diagrama\%C3\%A7\%C3\%A3o_Final_\%2008_08_2013_3.pdf>. Acesso em: 25 jun. 2014.

ALMOND, Gabriel; VERBA, Sidney. The Civic Cuture: Political Attitudes and Democracy in Five Nations. California: Sage Publications, 1963.

BAQUERO, Marcello. Obstáculos Formais à Democracia Social: poliarquia, cultura política e capital social no Brasil. GONZÁLEZ, Rodrigo S. (Org.). In: Perspectivas sobre Participação e Democracia no Brasil. Ijuí: Ed. Unijuí, 2007. p. 55-80.

Democracia, juventude e capital social no Brasil. Porto Alegre: UFRGS, 2004.

BAQUERO, Marcello; VASCONCELOS, Camila. Crise de representação política, o surgimento da antipolítica e os movimentos antipartidarismo no Brasil. In: COMPOLITICA - Congresso da Associação Brasileira de Pesquisadores em Comunicação e Política, 5, Curitiba, 2013. Disponível em: <http://www.compolitica.org/home/?page_id=1100>. Acesso em: 25 jun. 2014.

BAQUERO, Marcello; BAQUERO, Rute. Trazendo o cidadão para a arena pública: Capital Social e empoderamento na produção de uma democracia social na América Latina. Revista Redes, Santa Cruz do Sul, v. 12, n. 1, p. 125-150, jan.-abr. 2007.

BAQUERO, Marcello; AMORIM, Maria S. Cultura política fragmentada: o papel do capital social na democratização brasileira. Sociedade e Cultura, Goiânia, v. 7, n. 1, p. 9-20, jan.-jun. 2004.

BAQUERO, Marcello; PRÁ, Jussara. Democracia brasileira e cultura politica no Rio Grande do Sui. Porto Alegre: Ed. UFRGS, 2007.

BRASIL. Lei No 11.129, de 30 de junho de 2005. Institui o Programa Nacional de Inclusão de Jovens - ProJovem; cria o Conselho Nacional da Juventude - CNJ e a Secretaria Nacional de Juventude; altera as Leis nos 10.683, de 28 de maio de 2003, e 10.429, de 24 de abril de 2002; e dá outras providências. Disponível em: <http://www.planalto.gov.br/ccivil_03/_Ato20042006/2005/Lei/L11129.htm> Acesso em: 04 mai. 2013.

Lei n. 12.852, de 5 de agosto de 2013. Institui o Estatuto da Juventude e dispóe sobre os direitos dos jovens, os princípios e diretrizes das políticas públicas de juventude e o Sistema Nacional de Juventude - SINAJUVE. Disponível em: <http://www.planalto.gov.br/ccivil_03/_Ato2011-2014/2013/Lei/L12852.htm>. Acesso em: 02 jun. 2014.

CARRERAS, Miguel; CASTANEDA-ANGARITA, Néstor. Recursos dos eleitores e participação eleitoral na América Latina. Em Debate, Belo Horizonte, v. 4, n. 3, p. 25-40, 2012.

CASTRO, Mary G.; ABRAMOVAY, Miriam. Por um Novo Paradigma do Fazer Políticas: Políticas de/para/com juventudes. Revista Brasileira de Estudos de População, v.19, n. 2, jul./dez. 2002.

CEPAL. Capítulo V: Análise de algumas variáveis subjetivas da coesão social. In: Coesão Social: Inclusão e Sentido de Pertencer na América Latina e no Caribe. 2007. Disponível em: <http://www.cepal.org/publicaciones/xml/4/29354/Cap5Cohesionpr.pdf>. Acesso em: 09 mai. 2014.

CUNHA, Patrícia R. C. da. A participação do Banco Mundial na formação cidadã dos jovens cearenses. 2005. 157 p. Dissertação (Mestrado em Ciência Política) - Programa de Pós-graduação em Ciência Política, Universidade Federal do Rio Grande do Sul, Porto Alegre, 2005. 
FEE. Fundação de Economia e Estatística do Rio Grande do Sul. Estatísticas População. 2013. Disponível em: <http://www.fee.tche.br/sitefee/pt/content/estatisticas/pg_populacao.php>. Acesso: 4 out. 2013.

FIGUEIREDO, Marcus F. A decisão do voto: democracia e racionalidade. Belo Horizonte: Editora UFMG, 2008.

G1. Veja pesquisa completa do Ibope sobre os manifestantes. São Paulo: G1, 24 jun. 2013. Disponível em: <http:/g1.globo.com/brasil/noticia/2013/06/veja-integra-da-pesquisa-do-ibope-sobre-osmanifestantes.html>. Acesso em: 08 nov. 2013.

GROPPO, Luís A. Juventude: Ensaios sobre sociologia e história das juventudes modernas. Rio de Janeiro: Difel, 2000.

HARDMANN, Elis R. H. O Eleitor brasileiro: uma análise do comportamento eleitoral. 2001. 285p. Dissertação (Mestrado em Ciência Política) - Programa de Pós-graduação em Ciência Política, Universidade Federal do Rio Grande do Sul, Porto Alegre, 2001.

HOPENHAYN, Martín. América Latina desigual y descentrada. Bogotá: Grupo Editorial Norma, 2005.

IBASE. Instituto Brasileiro de Análises Sociais e Econômicas. Pesquisa sobre Juventudes no Brasil. IBASE/Instituto Polis, 2008.

IBGE. Instituto Brasileiro de Economia e Estatística. Censo 2010. Disponível em: <http://censo2010.ibge.gov.br/> Acesso em: 21 mai. 2014.

KEIL, Ivete M. Dos Jovens contestadores aos jovens de hoje - Uma nova forma de participação na pólis? In: BAQUERO, Marcello (Org.). Democracia, juventude e capital social no Brasil. Porto Alegre: UFRGS, 2004. p. 17-48.

LESSA, Renato. Palestra Representação Política: Fundamentos e Crise. 23 nov. 2009. Disponível em: <http:/www.cpflcultura.com.br/wp/2009/11/23/representacao-politica-fundamentos-e-criserenato-lessa-2/>. Acesso em: 15 jun. 2014

LUCAS, João I. P. Juventude e antipolítica no Brasil: um estudo de cultura política e ideologia. $2004 a$. 220 p. Tese (Doutorado em Ciência Política) - Programa de Pós-Graduação em Ciência Política, Universidade Federal do Rio Grande do Sul, Porto Alegre, 2004 a.

. Orçamento participativo, capital social e antipolítica: um estudo de caso em Caxias do Sul. In: BAQUERO, Marcello (Org.). Democracia, Juventude e Capital Social no Brasil. Porto Alegre: UFRGS, 2004b. p. 180-207.

MANNHEIM, Karl. O problema sociológico das geraçóes. Tradução de Cláudio Marcondes. In: FORACCHI, Marialice M. (Org.). Karl Mannheim: Sociologia. São Paulo: Ática, 1982. p. 67-95.

MILL, John S. Textos de Stuart Mill. In: WEFFORT, Francisco C. (Org.). Os clássicos da política. Vol. 2. São Paulo: Editora Ática, 2000. 200-223p.

NAZZARI, Rosana K. Juventude brasileira: capital social, cultura e socialização política. Cascavel: EDUNIOESTE, 2006.

NICOLAU, Jairo. A Participação Eleitoral no Brasil. Working Paper Series - University of Oxford Centre for Brazilian Studies, n. 26, 2002. Disponível em: <http://www.lac.ox.ac.uk/sites/sias/files/documents/Nicolau26.pdf>. Acesso em: 31 mai. 2014.

NICOLETTI, André S. A presença jovem nas Câmaras de Vereadores dos municípios que compóe a Azonasul nas eleiçôes de 2008: trajetória e participação política. 2013. 134p. Dissertação (Mestrado em Ciência Política) - Programa de Pós-Graduação em Ciência Política, Universidade Federal de Pelotas, Pelotas, 2013. 
PINHEIRO, Ângela de A. A Criança e o adolescente como sujeitos de direitos: emergência e consolidação de uma representação social no Brasil. In: CASTRO, Lucia R. de (Org.). Crianças e jovens na construção da cultura. $1^{\text {a }} \mathrm{ed}$. Rio de Janeiro: NAU Editora/FAPERJ, 2001. p. 45-68.

PASQUINO, Gianfranco. Comportamentismo. In: BOBBIO, Norberto; MATTEUCCI, Nicola; PASQUINO, Gianfranco (Orgs.). Dicionário de Política. Vol. 1. Brasília: Editora UnB, 2000.

POWER, Timothy J.; JAMISON, Giselle D. Desconfiança política na América Latina. Opinião Pública, Campinas, v. 11, n. 1, p. 64-93, mar. 2005.

RANINCHESKI, Sonia. Capital Social e Cultura Política em Tempos de Crise Econômica: os casos de Brasil e Uruguai. In: BAQUERO, Marcello. (Org.). Capital social, desenvolvimento sustentável e democracia na América Latina. Porto Alegre: Editora da UFRGS, 2007.

RENNÓ JR, Lúcio R. Revisitando a corrente dominante da teoria da cultura política. In: Pós: Revista Brasiliense de Pós-Graduação em Ciências Sociais. Brasília, n囚 1, 1997.

RIBEIRO, Ednaldo; BORBA, Juliana; SILVA, Rafael da. Comparecimento Eleitoral na América Latina: uma análise multinivel comparada. In: ANPOCS - Encontro Anual, 36, Águas de Lindóia, 2012. Disponível em: $<$ http://portal.anpocs.org/portal/index.php?option=com_docman\&task=doc_view\&gid=7838\&Ite mid=217>. Acesso em: 3 out. 2013.

SALLES, Denise. Comparecimento Eleitoral e Cultura Política no Brasil. Em Debate, Belo Horizonte. v. 2, n. 7, p. 16-20, jul. 2010.

SCHMIDT, João P. Os jovens e a construção de capital social no Brasil. In: BAQUERO, Marcello (Org.). Democracia, juventude e capital social no Brasil. Porto Alegre: UFRGS, 2004.

. Juventude e Política no Brasil: a socialização política dos jovens na virada do milênio. Santa Cruz do Sul: EDUNISC-RS, 2001.

SCHUMPETER, Joseph. Capitalismo, socialismo e democracia. Rio de Janeiro: Fundo de Cultura, 1961.

SPOSITO, Marilia P. Os Jovens no Brasil: desigualdades multiplicadas e novas demandas políticas. São Paulo: Ação Educativa, 2003.

VALDIVIESO, Patricio; LÓPEZ. Miguel A. Evidencias en torno al Capital Social, la participación y la confianza - estudio sobre el caso de Chile. In: BAQUERO, Marcello (Org.). Capital social, desenvolvimento sustentável e democracia na América Latina. Porto Alegre: Editora da UFRGS, 2007.

TSE. Tribunal Superior Eleitoral. Estatísticas de eleitorado. 2014. Disponível em: $<$ http://www.tse.jus.br/eleitor/estatisticas-de-eleitorado/estatistica-do-eleitorado-por-sexo-e-faixaetaria>. Acesso em: 03 jun. 2014.

Texto recebido em 26 de julho 2014. Aprovado em 15 de agosto de 2014. 